PONTIFÍCIA UNIVERSIDADE CATÓLICA DO RIO DE JANEIRO

\title{
Valuation da empresa Iguatemi
}

André Osorio Guimarães da Silva

Trabalho de Conclusão de Curso

Centro de ClênCIAS SOCIAIS - CCS

DePARTAMENTO de AdMINISTRAÇÃo

Graduação em Administração de Empresas 


\title{
André Osorio Guimarães da Silva
}

\section{Valuation da empresa Iguatemi}

\author{
Trabalho de Conclusão de Curso
}

Trabalho de Conclusão de Curso, apresentado ao programa de graduação em Administração da PUC-Rio como requisito parcial para a obtenção do titulo de graduação em Administração.

Orientador(a): Professor Marcelo Cabus Klotzle

Rio de Janeiro, junho de 2021. 


\section{Agradecimentos}

Gostaria de agradecer à minha família, amigos, professores e meu orientador, Marcelo Klotzle, não só pelo apoio neste trabalho, mas pelo suporte durante os últimos 4 anos de estudos. 


\title{
Resumo
}

Osorio, André. Valuation da empresa Iguatemi. Rio de Janeiro, 2021. 37 p. Trabalho de Conclusão de Curso - Departamento de Administração. Pontifícia Universidade Católica do Rio de Janeiro.

O trabalho teve como objetivo calcular o preço justo da ação IGTA3 por meio do valuation pelo método do Fluxo de Caixa Descontado. As premissas que foram cruciais e base para o valuation foram criadas através de pesquisas por relatórios da empresa, estudos de setor e as demonstrações financeiras da mesma, visando precificar a empresa da forma mais conservadora possível.

O valuation de IGTA3 se mostrou bastante razoável considerando as informações base utilizadas (reportes do início de 2021 e DFs de fechamento de 2020), ao chegarmos a um preço de $R \$ 36,24$, apenas $3,20 \%$ inferior ao preço ao qual a ação estava cotada no fechamento do $1^{\circ}$ Trimestre de 2021 , de $\mathrm{R} \$$ 37,40 .

\author{
Palavras- chave \\ Iguatemi, Shopping Centers, Fluxo de Caixa Descontado, Valuation
}

\section{Abstract}

Osorio, André. Valuation da empresa Iguatemi. Rio de Janeiro, 2021. 37 p. Trabalho de Conclusão de Curso - Departamento de Administração. Pontifícia Universidade Católica do Rio de Janeiro.

The main objective of this study was to figure out the true equity value of IGTA3 through de Discounted Cash Flow Valuation method. Different materials were utilized throughout the study in order to figure out the ideal conservative premises to be used in the valuation, including the companies' financial statements, sector studies and markets reports.

The valuation resulted in a reasonable stock price of $\mathrm{R} \$ 36,24$, considering the information utilized (beginning of 2021 and Financial Statements from the closing of 2020), and that the stock price at the end of the first Trimester for the company was $R \$ 37,40$, only $3,20 \%$ higher.

\section{Key-words}

Iguatemi, Shopping Centers, Discounted Cash Flow, Valuation 


\section{Sumário}

10 tema e o problema de estudo 1

1.1. Introdução ao tema e ao problema do estudo 1

1.2. Contexto 3

1.3. Objetivo do estudo 4

1.4. Delimitação e foco do estudo 4

1.5. Justificativa e relevância do estudo 5

2 Referencial Teórico 6

2.1. Fundamentos de Valuation 6

2.2. Método de fluxo de caixa descontado 6

2.2.1. Projeção de fluxo de caixa livre 7

2.2.2. Definição da taxa de desconto (WACC) 7

2.2.3. Fluxo de caixa descontado 8

2.2.4. Cálculo do VPL 8

2.3. Perpetuidade 9

3 Métodos e procedimentos de coleta e de análise de dados do estudo 11

3.1. Tipo de pesquisa 11

3.2. Pesquisa exploratória 11

3.3. Coleta de dados 11

3.4. Tratamento e análise de dados 12

4 Análise do Setor de Shopping Centers no Brasil 13

4.1. Análise do setor 13

4.2. Análise do setor durante a pandemia 16

5 Análise da Iguatemi 20

5.1. História 20

5.2. Operações 21

5.3. Governança Corporativa 22 
6 Valuation Iguatemi 26

6.1. Premissas 26

6.1.1. Crescimento 27

6.1.1.1. Crescimento em 2021

6.1.1.2. Crescimento após 2021

6.1.2. CAPEX 28

6.1.3. Custo de Dívida 28

6.1.4. Capital de Giro 29

6.1.5. Outras Premissas 30

6.2. DRE 30

6.3. WACC 31

6.4. Fluxo de Caixa Descontado 32

6.5. Perpetuidade 33

6.6. Valor por Ação 33

7 Considerações Finais $\quad 36$

8 Referências Bibliográficas 38

\section{Lista de figuras}

Figura 1- Comparativo SMAL11 e IGTA3 …..................................................... 3

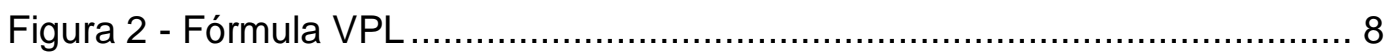

Figura 3 - Fórmula Perpetuidade .......................................................... 9

Figura 4 - Fórmula de Perpetuidade Descontada ........................................ 10

Figura 5 - Fórmula Valuation ................................................................ 10

Figura 6 - Crescimento de Empreendimentos e Inaugurações no setor de Shopping Centers....................................................................... 14

Figura 7 - Evolução de Faturamento em Shopping Centers ............................ 15

Figura 8 - Evolução de Vendas em Shopping Centers no Brasil ....................... 17 
Figura 9 - Estrutura de Acionistas da Iguatemi ............................................. 22

Figura 10 - Estrutura de Dívida da Iguatemi ............................................... 29

Figura 11 - DRE Projetada da Iguatemi.................................................. 31

Figura 12 - Fluxo de Caixa Descontado da Iguatemi .................................... 32

Figura 13 - Balanço Patrimonial da Iguatemi................................................ 34

Figura 14 - Valor Justo de IGTA3 ................................................................ 34 


\section{0 tema e o problema de estudo}

\subsection{Introdução ao tema e ao problema do estudo}

O objetivo deste trabalho é definir o valor correto de mercado para a empresa Iguatemi. Este valor "correto" é de extrema importância para decisões na esfera de negócios pelo fato de que nem sempre algo de fato vale aquilo que parece em um primeiro momento. Então, para determinarmos o valor da Iguatemi poderíamos apenas observar a cotação da mesma na Bolsa de Valores, B3. Porém, este valor seria o valor negociado pelo mercado, e não o valor da empresa em si. Para encontrarmos o valor da empresa em si, sem pensar em cotações de mercado que mudam constantemente, podemos utilizar o valuation,

Damodaran, também conhecido como o pai do valuation, define que existem três formas de calcularmos este valor, sendo elas: pelo valor intrínseco, valor relativo ou pelo valor de contingência de uma opção. Neste trabalho a metodologia de valuation utilizada será a do cálculo do valor da lguatemi através do valor intrínseco (DAMODARAN, 2007).

O valor intrínseco será atingido através da utilização do Discounted Cash Flow da Iguatemi, ou FCD (Fluxo de Caixa Descontado). Este método traz para valor presente o fluxo de caixa projetado da empresa, permitindo a avaliação de projeções pelos valores atuais, auxiliando no entendimento do valor da empresa no presente. Este método também é o mais comum dentro do ambiente do mercado, sendo uma metodologia mais prática do que as demais.

O valuation tem a importância e é essencial por trás de tomadas de decisão por permitir uma melhor visibilidade de um ativo, seja de um gestor de um veículo de Private Equity ou de um fundo aberto. Existem diversas empresas que podem ser adquiridas tanto no âmbito privado quanto no âmbito público, e ao entender o quanto essas empresas de fato valem, qual é o retorno esperado de cada uma, dentre outros fatores e indicadores, o gestor pode tomar uma decisão mais assertiva sobre qual poderá lhe render os melhores frutos no futuro. Através deste método, o gestor pode mais facilmente perceber empresas 
que estão sobre avaliadas pelo mercado e também aquelas que estão subavaliadas e que podem ser as próximas aquisições do mesmo.

Existe uma certa subjetividade no processo de valuation todavia, uma vez que as premissas definidas variam de profissional para profissional. Um gestor pode entender que a economia terá um recesso nos próximos 5 anos, estipulando taxas de retorno baixar ou até negativas para as receitas de uma empresa, enquanto seu par acredita que a economia terá um ambiente favorável nos mesmos 5 anos e então projeta taxas favoráveis de retornos e lucros para a empresa. Por isso, o acesso à informação e o interesse por entrar em maiores detalhes no assunto que for é sempre crucial, podendo definir sucesso na tentativa de avaliar um ativo ou o fracasso do mesmo. É durante este processo que um profissional deve focar $100 \%$ de seus esforços, afim de projetar os valores mais perto da realidade possível, afim de obter sucesso em sua alocação de recursos.

Este processo é ainda mais crucial dentro de um ambiente de mercado aberto como a Bolsa de Valores, já que, como explicado anteriormente, diferentes investidores muitas vezes divergem em suas percepções e avaliações de ativos e do mercado em si. Ademais, ativos negociados em Bolsa de Valores podem muitas vezes sofrer com a percepção do público ou com noticias negativas que muitas vezes não afetam o negócio em si. Esses ruídos podem afetar fortemente o preço sendo negociado das mesmas, prejudicando aqueles que não tem uma base fundamentada de que o ativo de fato vale mais do que o preço da ação no momento (ou até em casos de positivismo exacerbado, que a ação vale menos do que está sendo negociada). O valor intrínseco, resultado do valuation, é essencial nestes momentos, dando uma ideia mais clara e objetiva de qual deve ser o próximo passo do investidor.

Momentos de crise também servem de evidência para mostrar a efetividade do valuation, uma vez que tivemos quedas vertiginosas nos preços negociados de empresas que não foram de jeito algum afetadas pelo Coronavírus. É claro que muitas empresas foram prejudicadas, "merecendo" a desvalorização de suas ações, mas outras viram quedas em suas ações por nenhuma razão diferente de que pelo mercado estar caindo como um todo, elas caíram junto. Assim, ao criar um modelo de valuation adequado, seria possível observar as inconsistências presentes na Bolsa de Valores, resultando em uma tomada de decisão mais aprofundada e, possivelmente, melhor do que uma decisão baseada apenas nos preços praticados na B3. 


\subsection{Contexto}

A Iguatemi Empresa de Shopping Centers S.A. atua no setor de shopping centers brasileiro há mais de 40 anos, sendo um dos players mais relevantes do mesmo e estando entre as 60 marcas mais valiosas do país.

Para se ter uma melhor visibilidade da empresa e de seu patamar de preço atual, é interessante também analisar um índice na qual a mesma está inserida, visando contextualizar sua precificação e movimentação em sua cotação dentro de um ambiente mais amplo. Para tanto, o ETF SMAL11, negociado na Bolsa de Valores B3, foi escolhido.

O ETF SMAL11 é um Exchange traded fund composto por ações das empresas consideradas Small Caps de maior expressão negociadas na B3, pertencentes ao índice SMLL da B3. A Iguatemi atualmente faz parte deste ETF e deste segmento do mercado, compondo 0,989\% do SMAL11 (B3, 2021).

Abaixo pode-se observar o comportamento da Iguatemi, IGTA3 (azul), comparado com o comportamento do ETF SMAL11 (verde), nos últimos 5 anos de negociação (YAHOO FINANCE, 2021):

\section{Figura 1- Comparativo SMAL11 e IGTA3}

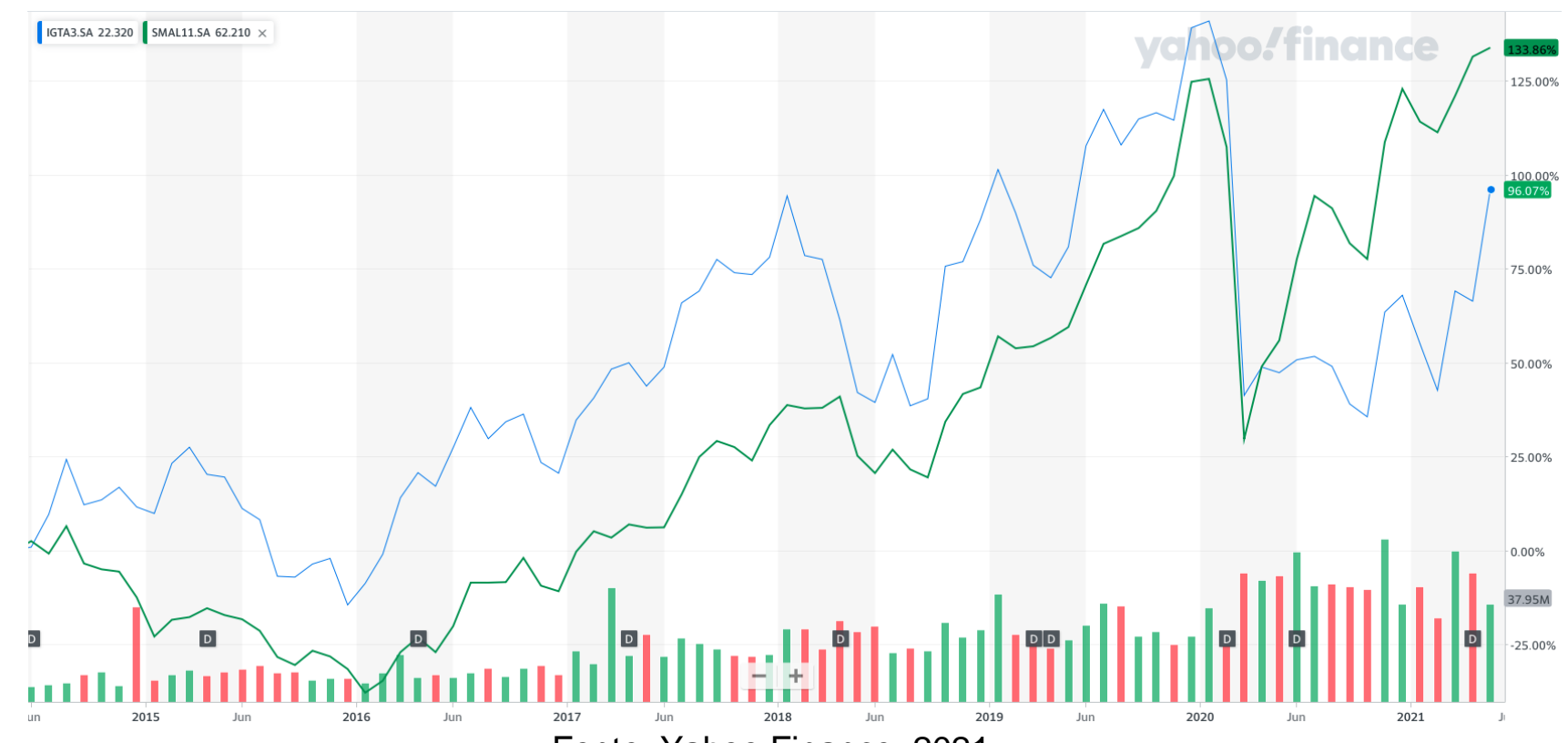

Fonte: Yahoo Finance, 2021

Tanto a empresa quanto o ETF sofreram bastante volatilidade no período. Um dos fatores que explica essa volatilidade é que o ETF é composto por 
empresas menores quando comparadas às empresas mais sólidas e de maior porte de um ETF como o BOVA11 por exemplo, e a Iguatemi tende a sofrer também com isso. Então, pode-se deduzir que ao longo do tempo a volatilidade é algo a ser esperado e que o valuation neste caso é imprescindível, uma vez que não se pode "confiar" no mercado nestes casos. Há de se aprofundar no estudo de um papel como o IGTA3, afim de aproveitar as oportunidades dadas pelo mercado e para se entender quando a margem oferecida pelo mercado já é mais do que deveria ser, no caso de uma sobre avaliação em momentos.

Um ponto no gráfico que exemplifica perfeitamente esta volatilidade, e que acabou valendo não só para as Small Caps no ano passado, mas para as Mid e Large Caps também, foi a queda abrupta em março, por conta do Coronavírus. Para a Iguatemi esta queda fez mais sentido até do que para muitas outras empresas, que não foram impactadas negativamente ou até sofreram impactos positivos com a pandemia, mas que foram precificadas no chão uma vez que os casos chegaram ao país.

Com isso, chegamos à pergunta essencial para seguirmos em frente com este estudo: Qual é o valor da Iguatemi Shopping Centers S.A. ao calcular seu valor intrínseco pelo método de FCD (Fluxo de Caixa Descontado)?

\subsection{Objetivo do estudo}

O objetivo principal do estudo é, novamente, encontrar o valor intrínseco da Iguatemi Empresa de Shopping Centers S.A. através do valuation da mesma pelo método do Fluxo de Caixa Descontado. Desta forma, qualquer ruído que pode impactar a cotação da mesma é isolado e evitamos impactos negativos no valor real da lguatemi causados por negociações baseadas na demanda do papel, e não em seu valor intrínseco.

\subsection{Delimitação e foco do estudo}

O estudo trará o cálculo do valor intrínseco da empresa Iguatemi Empresa de Shopping Centers S.A. através de premissas criadas de forma independente pelo autor, utilizando um estudo de mercado do setor de Administração de Shopping Centers, análise da Iguatemi como empresa e indicadores de mercado projetados para os próximos exercícios. 


\subsection{Justificativa e relevância do estudo}

A relevância deste estudo se deve à crise que o mercado brasileiro, assim como todos os mercados mundiais, passou neste último ano. O setor de Administradoras de Shopping Centers foi um dos setores mais afetados pela pandemia, muito pelo fato de que os shopping centers permaneceram fechados durante meses no ano de 2020. O impacto da crise do Coronavírus no setor será detalhado no capítulo 4 abaixo.

Devido a estes pontos, é importante entender se a queda na cotação da Iguatemi no último ano foi justificável e até se a recuperação desde março/2020 é uma reflexão do valor intrínseco da empresa, ou apenas movimentação do mercado devido a ruídos externos. O valuation auxiliará neste ponto, embasando o preço atual, especialmente durante este período de alta volatilidade pelo qual o mercado ainda está passando ainda por conta dos reflexos da Covid-19.

O estudo será estruturado em 7 capítulos. O capítulo 2, ou referencial teórico explicará o valuation e estará situado após esta introdução. 0 capítulo 3 será composto pela metodologia de pesquisa e como este estudo será realizado. O capítulo 4 apresentará a análise do setor de administradoras de shopping centers, seguido pelo capítulo 5 onde será feita a análise da Iguatemi Empresa de Shopping Centers S.A. O capítulo 6 será composto pelo estudo do valuation em si e discorrerá sobre as premissas utilizadas para chegar no valor intrínseco da empresa. Por fim, o capítulo 7 irá expor as considerações finais e apresentará o conhecimento adquirido ao realizar o estudo. 


\section{Referencial Teórico}

Este capítulo abordará todos os conceitos e processos utilizados no valuation da Iguatemi. O objetivo do capítulo é explicar a teoria por trás da precificação da empresa escolhida

O capítulo será em três seções distintas, sendo elas fundamentos do processo de valuation, fluxo de caixa descontado e perpetuidade no modelo.

\subsection{Fundamentos de Valuation}

Os fundamentos mais importantes do valuation são dois fatores que permitem traçar o quanto um ativo vale hoje baseado nas suas perspectivas de longo prazo, o tempo e a taxa de desconto (DAMODARAN, 2007). Estas duas variáveis fazem toda a diferença no momento em que um ativo é avaliado pelo método do fluxo de caixa descontado, uma vez que determinam qual será o desconto deste papel e por quanto tempo ele será exposto a projeções que podem ou não ser bem embasadas.

A variável do tempo é equivalente a quantos anos serão utilizados no fluxo de caixa projetado, e, consequentemente, quantos anos de resultado serão considerados no Ano 0 do cálculo. Já a taxa de desconto é o custo de capital utilizado para carregar todos esses fluxos de caixa futuros projetados para o Ano 0 , criando o valor líquido do ativo no presente. Este custo de capital é influenciado por diversos fatores e pode ser estimado de forma mais conservadora ou arrojada, dependendo das perspectivas da empresa em questão.

\subsection{Método de fluxo de caixa descontado}

O método do fluxo de caixa descontado é de extrema importância quando se quer entender o valor intrínseco de uma empresa ou de um projeto a ser realizado. Neste caso, permitirá entender o valor real da Iguatemi Shopping Centers S.A., independente do preço ao qual a empresa está sendo negociada atualmente na B3. 
Existe um processo para se adquirir o fluxo de caixa descontado de uma empresa que conta com os seguintes passos: projeção do fluxo de caixa livre, cálculo da taxa de desconto (WACC) a ser utilizada, cálculo do fluxo de caixa descontado, e, por último, o cálculo do VPL da empresa/projeto.

\subsubsection{Projeção de fluxo de caixa livre}

Seguindo o processo listado acima, iniciamos com a projeção do fluxo de caixa livre da empresa. O fluxo de caixa livre de um determinado ano da empresa/projeto é encontrado ao projetar a DRE de anos futuros, somando as receitas e despesas. Essas projeções utilizam dados de mercado e da empresa para trazerem números mais próximos da realidade e possibilidade para o ativo em questão. Então, é possível definir quanto deve se esperar de resultado para cada ano futuro, auxiliando a projeção do valor presente da mesma.

\subsubsection{Definição da taxa de desconto (WACC)}

Em um segundo momento, é necessário entender qual taxa será utilizada para carregar os fluxos projetados de volta ao Ano 0. Essa taxa de desconto representa o custo de capital do ativo e é comumente calculada através do WACC, ou weighted average cost of capital. O WACC é uma métrica confiável para se calcular a taxa de desconto de um ativo pelo fato de que ele considera tanto o custo de capital própria da empresa/projeto, quanto o custo de capital de terceiros, ou empréstimos contratados pela empresa em questão. Com isso, segue abaixo a fórmula do WACC e a definição de cada variável:

$$
W A C C=(C T \times K d)+(C P \times K e)
$$

Onde:

$$
\begin{aligned}
& \mathrm{CT}=\text { Capital de Terceiros / Patrimônio Líquido da Empresa } \\
& \begin{array}{r}
\mathrm{CP}=1-\mathrm{CT}=\text { Capital Próprio / Patrimônio Líquido } \\
\mathrm{Kd}=\mathrm{Kt} \times(1-\alpha) \rightarrow \text { Custo líquido de Capital de Terceiros } \\
\mathrm{Kt}=\text { taxa de empréstimo ponderada } \\
\alpha=\text { alíquota de imposto considerada }
\end{array}
\end{aligned}
$$




$$
\begin{gathered}
\mathrm{Ke}=\mathrm{Rf}+(\mathrm{Rm}-\mathrm{Rf}) \beta \rightarrow \text { CAPM (Capital Asset Pricing Model) } \\
\mathrm{Rf}=\text { Taxa Livre de Risco } \\
\mathrm{Rm}=\text { Taxa de Retorno de Mercado } \\
\beta=\text { Coeficiente de Risco de Mercado }
\end{gathered}
$$

\subsubsection{Fluxo de caixa descontado}

Ao calcular o fluxo de caixa livre e o custo de capital, ou WACC, é possível seguir para o terceiro passo, o cálculo do fluxo de caixa descontado, ou FCD. Neste passo, utiliza-se o WACC definido para carregar cada fluxo de caixa livre de cada ano para o Ano 0, encontrando o resultado que cada exercício teria no Ano 0 . Este cálculo possibilita a soma entre os diferentes anos, uma vez que não se pode somar valores de diferentes períodos sem que seja realizada algum tipo de equivalência.

O FCD é encontrado através da seguinte fórmula, descontando o fluxo de caixa livre pela taxa de desconto elevada ao ano do fluxo de caixa livre:

$$
\begin{aligned}
& F_{C D}=F C L_{N} /(1+r)^{N} \\
& \text { Onde: } \\
& F C L_{N}=\text { Fluxo de Caixa Livre no Ano } N \\
& r=\text { WACC }=\text { Taxa de Desconto }=(C T \times K d)+(C P \times K e)
\end{aligned}
$$

Ao utilizar a fórmula acima, pode-se evidenciar o impacto que a taxa de desconto e o tempo tem sobre os fluxos de caixa livres de cada ano.

\subsubsection{Cálculo do VPL}

O Valor Presente Líquido, ou VPL, é a soma dos fluxos de caixa descontados e o valor do investimento inicial realizado no Ano 0. O VPL é a representação do valor da empresa no momento atual, ao projetar os fluxos de caixa futuros da mesma. Assim, é possível entender o quanto essa empresa de fato vale em termos equivalentes. A fórmula do VPL se encontra abaixo:

Figura 2 - Fórmula VPL

$$
\sum_{1}^{n} \frac{F C L_{N}}{(1+r)^{N}}+I N V_{0}
$$


Fonte: Autor, 2021

A fórmula também pode ser escrita da seguinte maneira, facilitando sua interpretação:

$$
V P L=\left(F C D_{1}+F C D_{2}+F C D_{3}+F C D_{4}+\ldots+F C D_{N}\right)+I N V_{0}
$$

\subsection{Perpetuidade}

Devido ao fato de que uma empresa normalmente não nasce já visando uma data de encerramento, não seria possível calcular todos os fluxos de caixa projetados da mesma. É possível calcular até certo ano, e depois deve ser utilizado o método do fluxo de caixa perpétuo, calculando um fluxo de caixa padrão como se a empresa fosse existir para sempre. Ao final desta conta, o fluxo de caixa perpétuo é adicionado ao fluxo de caixa descontado calculado anteriormente, e então se tem o valor da empresa considerando sua possível perpetuidade.

Para calcular o fluxo de caixa livre perpétuo, ou FCLP, é necessário projetar uma taxa de crescimento adequada para o ativo, além da receita perpétua estimada para o mesmo. Tendo a taxa de crescimento e o e a receita, pode-se calcular o valuation ideal, mantendo em mente que a empresa pode continuar existindo por anos e anos, tornando inviável o cálculo de ano em ano.

Utilizando o Modelo de Perpetuidade com Crescimento de Gordon, podese entender que o FCLP será resultado da multiplicação do último fluxo de caixa livre projetado por $1+\mathrm{g}$, e divisão deste pela subtração da taxa de crescimento perpétuo da taxa de desconto, ou WACC (BREALEY, MYERS, ALLEN, 2017). A fórmula pode ser melhor evidenciada abaixo:

\section{Figura 3 - Fórmula Perpetuidade}

Perpetuidade $(\mathrm{FCLP})=\frac{F C L_{n-1} *(1+g)}{r-g}$

Fonte: Autor, 2021

$\mathrm{FCL}_{n-1}=$ Último Fluxo de Caixa Livre Projetado

$\mathrm{g}=$ Taxa de crescimento

$r=$ WACC $=$ Taxa de Desconto 
Ao calcular o valor da perpetuidade, é necessário carregar o mesmo para o valor presente, permitindo que o mesmo seja somado ao Fluxo de Caixa Descontado dos demais anos e ao investimento inicial no Ano 0. Este Fluxo de Caixa Descontado consequentemente se torna em um Fluxo de Caixa Livre Perpétuo, indicando que será o equivalente ao valor perpétuo da empresa/projeto estudado. Abaixo as fórmulas para melhor visualização do processo, considerando uma projeção de FCL de 4 anos, e, após o $4^{\circ}$ Ano, a projeção da perpetuidade.

$$
\mathrm{VPL}=\left(F C D_{1}+F C D_{2}+F C D_{3}+F C D_{4}\right)+\mathrm{INV}_{0}
$$

\section{Figura 4 - Fórmula de Perpetuidade Descontada}

$$
\text { Perpetuidade }=\text { FCLPD }=\frac{\left(\frac{F C L_{n-1} *(1+g)}{r-g}\right)}{\left[(1+r)^{4}\right]}
$$

Fonte: Autor, 2021

\section{Figura 5 - Fórmula Valuation}

$$
\text { Valuation }=\left[\left(\mathrm{FCD}_{1}+\mathrm{FCD}_{2}+\mathrm{FCD}_{3}+\mathrm{FCD}_{4}\right)+\mathrm{INV}_{0}\right]+\left[\frac{\left(\frac{F C L_{n-1} *(1+g)}{r-g}\right)}{\left[(1+r)^{4}\right]}\right]
$$

Fonte: Autor, 2021 


\section{Métodos e procedimentos de coleta e de análise de dados do estudo}

O capítulo abaixo visa abordar o método de pesquisa utilizado para o estudo, além do desenvolvimento do mesmo e a coleta de dados que foi realizada.

\subsection{Tipo de pesquisa}

Existem 3 tipos de pesquisa de mercado que podem ser conduzidas: pesquisa exploratória, pesquisa descritiva e pesquisa experimental. Essa pesquisa, independente de qual seja, é a coleta sistemática e análise dos dados sobre hábitos, atitudes, valores de consumidores e comportamentos (SOBRAL E PECI, 2013).

\subsection{Pesquisa exploratória}

O método de pesquisa a ser utilizado neste estudo será a pesquisa exploratória. Este método foi escolhido pelo fato de que proporciona maior familiaridade sobre o assunto para quem está elaborando o estudo, permitindo que as premissas a serem escolhidas sejam mais assertivas e reflitam melhor 0 ambiente do mercado como um todo.

O contraste entre a pesquisa exploratória e a pesquisa descritiva é que a descritiva busca elementos de causa e efeito na questão estudada, diferente da exploratória que busca o máximo de informação possível para possibilitar decisões e opiniões mais bem fundadas a respeito do problema central da pesquisa (SOBRAL E PECI, 2013).

\subsection{Coleta de dados}

Devido ao fato de que o valuation de uma empresa requer dados de empresas junto de premissas e projeções, podemos considerar que os dados coletados serão quantitativos e qualitativos. Não seria possível elaborar um valuation apenas através de dados quantitativos ou apenas dados qualitativos. 
Os dados quantitativos são recolhidos em um primeiro momento, analisados, e os dados qualitativos são elaborados através dos resultados e números.

A coleta destes dados quantitativos é realizada através do site de Relações com Investidores da Iguatemi, sites de informações e research financeiro, bancos de dados, entre outros. Ademais, muitos dados qualitativos são gerados durante o estudo, porém outros como previsões de indicadores e de mercado podem ser adquiridas através de reports de empresas ligadas ao setor, projeções macroeconômicas de instituições governamentais e do setor privado, entre outros.

Por se tratar de um valuation de uma empresa de capital aberto, estes dados são bastante facilitados e é possível utilizar análises secundárias para embasar as previsões e projeções ao longo do estudo.

\subsection{Tratamento e análise de dados}

Através do site de Relações com Investidores da Iguatemi, foi possível colher todos os dados que serão utilizados nas elaborações de DRE e Balanço Patrimonial, compondo os dados quantitativos necessários para o estudo.

Já os dados qualitativos serão colhidos através dos relatórios de mercado e setor estudados, press releases da Iguatemi e análises secundárias da empresa, possibilitando a criação de premissas bem fundamentadas. Estas premissas serão extremamente importantes na projeção de resultados futuros e crescimento não só da Iguatemi, mas também do setor de Administração de Shopping Centers. 


\section{Análise do Setor de Shopping Centers no Brasil}

O setor de shopping centers no Brasil é diferenciado do setor em outras partes do mundo. Em outros países, shopping centers são encontrados em locais mais remotos, onde as pessoas vão predominantemente para fazer compras, com alvos específicos determinados.

No Brasil, as pessoas tem o costume mais diário de ir a shopping centers em busca não só de compras específicas, mas também em busca de lazer, arcondicionado e alimentação. Não é à toa que temos diversos shopping centers localizados em grandes centros urbanos, onde eles são mais utilizados do que seriam caso fosse necessário o transporte de carro ou ônibus para chegar até os mesmos. Estes complexos otimizam os espaços urbanos cada vez mais escassos, e permitem maior segurança para os frequentadores (FASHION NETWORK, 2017).

Dado estes pontos, vale um estudo mais profundo de um setor extremamente importante para a economia e cultura do país, afim de entender o papel da empresa Iguatemi dentro do mesmo.

\subsection{Análise do setor}

O setor de shopping centers é um setor extremamente dependente do desempenho econômico do país. Em termos simplificados, se a economia vai bem e os brasileiros estão confiantes de que continuarão recebendo, o público tende a frequentar mais shoppings e a aumentar os lucros do mesmo como consequência. Em contrapartida, quanto temos um período econômico turbulento, as compras tendem a diminuir, devido aos menores recursos à disposição da população, e à necessidade de poupar mais, já que não se sabe quanto a economia retomará seu crescimento.

Assim, pode-se entender que é um setor cíclico, e as empresas dentro do setor são altamente dependentes de diversos fatores externos. Isso impacta fortemente no potencial que as empresas envolvidas tem de crescimento, ainda mais quando nos encontramos em momentos atípicos, como o período de 20202021. 
Total de empreendimentos e inaugurações por ano

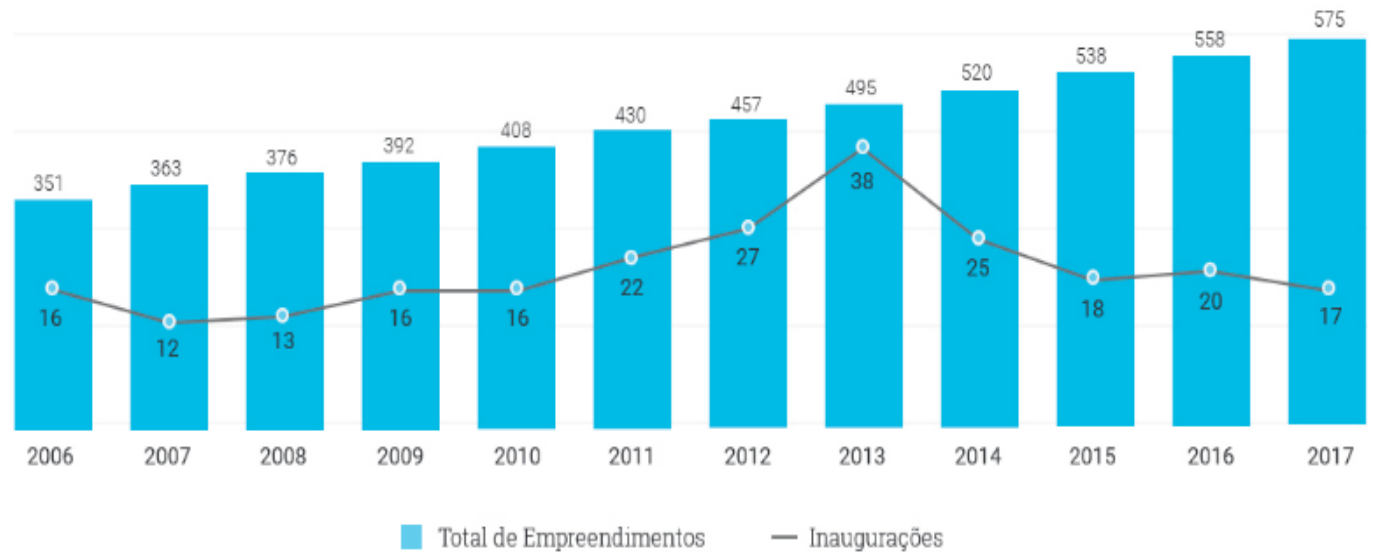

Os três grandes players do setor de shopping centers no Brasil são Iguatemi, BR Malls e Multiplan. Os valores de mercado estimados destas três empresas são de $R \$ \frac{6.500 .000 .000,00,}{R} \$ \mathbf{8 . 7 0 0 . 0 0 0 . 0 0 0 , 0 0}$ e $R \$$ 14.500.000.000,00, respectivamente (STATUS INVEST, 2021).

Estas três empresas são responsáveis por shoppings conhecidos em grandes centros urbanos brasileiros, como o JK Iguatemi em São Paulo (Iguatemi), Shopping Tijuca no Rio de Janeiro (BR Malls) e Barra Shopping no Rio de Janeiro (Multiplan).

O setor tem hoje por volta de 600 shopping centers, distribuídos entre os diversos administradores, com mais de 10 shoppings projetados ainda para 2021 (ABRASCE, 2021). Entendendo que dentro de cada um dos 600 shopping centers temos diversas lojas, restaurantes, cinemas, lanchonetes, etc., chegamos a um número impressionante de cerca de 340 milhões de visitantes por mês em média (contando cada ida ao shopping de cada pessoa, por isso o número maior do que a população brasileira).

Para se entender também a importância dos shopping centers para o

\section{Figura 6 - Crescimento de Empreendimentos e Inaugurações no setor de Shopping Centers}

público como um todo, e não apenas para aqueles que tem algo a comprar, a ABRASCE, Associação Brasileira de Shopping Centers, através de diversas pesquisas de campo, chegou a um número de 2.982 salas de cinema distribuídas pelos mais de 600 shopping centers do país. Ou seja, cada shopping center conta com algo próximo a 4 salas de cinema (em média), dando mais oportunidades ao público de usufruir de seus espaços para lazer.

Seguem alguns dados de crescimento do setor até o final de 2017 disponibilizados pela área de Relações com Investidores do Fundo de Investimento Imobiliário XP Malls, Ticker. XPML11 (XP MALLS, 2018): 


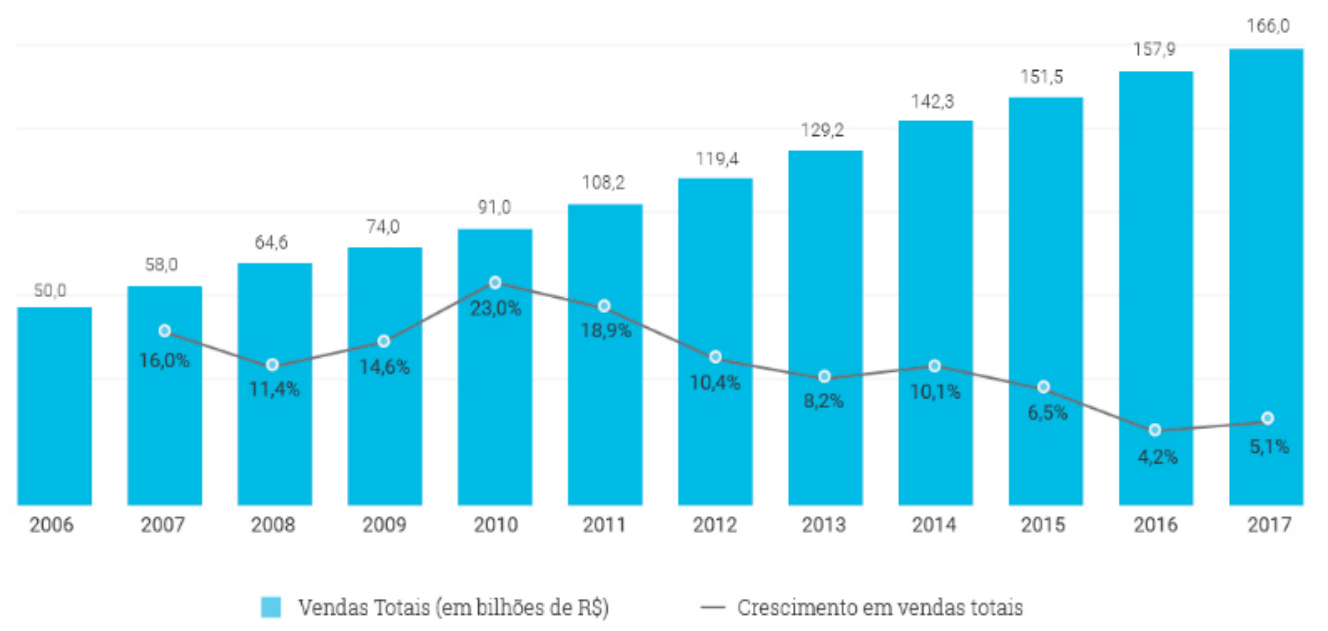

Fonte: XP Malls, 2018

Figura 7 - Evolução de Faturamento em Shopping Centers

Fonte: XP Malls, 2018

Pode-se perceber o crescimento não só nas inaugurações de novos shopping centers, mas também nos faturamentos dos mesmos.

A área de Relações com Investidores do XPML11 destaca também a importância do mix de lojas e empreendimentos dentro dos shopping centers. É explicitado mais uma vez a importância de serviços como alimentação e lazer, além das tradicionais lojas de roupas, artigos esportivos, óticas, etc. (XP MALLS, 2018)

O setor, até o final de 2019 vivia um bom momento, fechando o ano com um aumento de 7,9\% nas vendas e um faturamento de $\mathrm{R} \$ 192,8$ bilhões. Foram os melhores resultados do setor desde 2014, após um longo período em que a economia brasileira sofreu por diversos motivos (MERCADO E CONSUMO, 2020). Importante notar também que as classes mais altas, A e B, foram os maiores frequentadores dos shopping centers no ano de 2019, compondo aproximadamente $60 \%$ dos frequentadores, de acordo com a pesquisa do Mercado e Consumo.

Ainda na pesquisa do Mercado e Consumo estão os pontos frisados acima sobre os shopping centers serem mais do que apenas locais de compras no Brasil, servindo como "Complexos Multiuso", dando destaque aos condomínios empresariais (68\%), Hotéis (35\%) e Faculdades/Universidades (28\%) (MERCADO E CONSUMO, 2020). Então, entendemos mais uma vez a 
importância dos shopping centers para a população brasileira e os diversos usos que eles tem para todos.

Por mais que os números até 2019 tenham sido bons em termos de crescimento, o setor é muito influenciado pelas condições econômicas do país, como explicado acima. Ou seja, com o início da pandemia da Covid-19 era de se esperar que o setor fosse ser bastante prejudicado, porém os problemas foram "impulsionados" por todas as restrições impostas ao comércio, incluindo os shopping centers.

\subsection{Análise do setor durante a pandemia}

No mês de março de 2020 a pandemia do novo Coronavírus chegou ao Brasil, e com ela, todas as restrições que já vinham sendo adotadas no resto do mundo. Os comércios foram fechando aos poucos, depois os restaurantes, até que apenas o comércio de produtos essenciais como os de saúde poderiam permanecer abertos. Assim, podia se esperar que os shopping centers fossem ser muito prejudicados, porém ainda não havia o entendimento de por quanto tempo essa situação se prolongaria.

Agora em 2021 continuamos em uma situação indefinida, com restrições sendo impostas para diversos setores mesmo um ano após o início da pandemia. Por mais que os shopping centers já abriram diversas vezes neste um ano, quando a situação da saúde piora novamente eles voltam a fechar, causando uma incerteza enorme não só para o público, mas principalmente para as lojas localizadas dentro dos mesmos e para os administradores de shopping centers que dependem do comércio para faturarem.

Por conta de todos esses fatores, o setor de shopping centers vivenciou uma queda de $33,2 \%$ em seu faturamento no ano de 2020 , quando comparado ao ano de 2019, de acordo com a Confederação de Associações Comerciais e Empresariais do Brasil, ou CACB. O faturamento foi de $\mathrm{R} \$ 128,8$ bilhões em 2020 e de R\$192,8 bilhões em 2019 (ARRUDA, 2021).

O gráfico abaixo retirado do site G1 mostra a queda no crescimento dos shopping centers e deixa evidente o impacto relevante da pandemia para 0 setor: 
\% em relação ao ano anterior

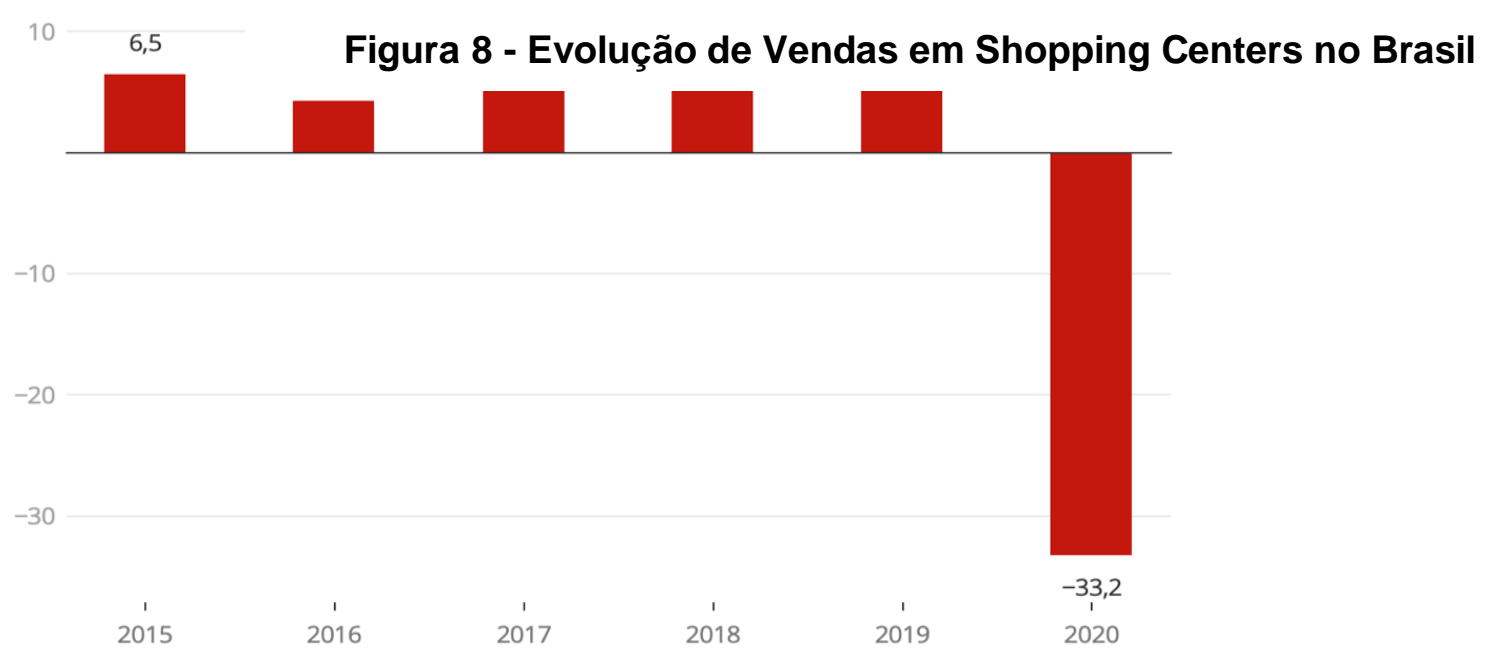

Fonte: G1, 2021

Depois de 5 anos consecutivos de crescimento por volta de $5,6 \%$, o setor teve um decréscimo de 33,2\%, um número extremamente desfavorável para todos os participantes no setor (G1, 2021).

A CACB aponta que pela redução nos horários de funcionamento dos shopping centers, houve uma redução nos quadros de funcionários dos estabelecimentos e lojas, resultando também em um decréscimo de 9,4\% em quantidade de novos empregos gerados pelos lojistas e restaurantes (ARRUDA, 2021).

Outro fator apontado pela Associação Brasileira de Shopping Centers é a baixa digitalização presente nos shopping centers brasileiros até o momento em que a pandemia começou. Até 2020 , apenas $29 \%$ dos empreendimentos tinham algum tipo de operação digital integrada para atender aos consumidores de forma não presencial. A expectativa é que destes que não tinham qualquer tipo de integração, ao menos 59\% devem instalar os chamados marketplaces em até 2 anos $(G 1,2021)$. Assim, os estabelecimentos migrarão cada vez mais para o mundo online, ficando menos reféns das condições de saúde que são um obstáculo atualmente. Isso não só auxiliará no momento atual de pandemia, mas prevenirá possíveis problemas futuros de qualquer natureza.

Este ponto é reflexivo pelo fato de que uma maior digitalização dos shopping centers poderia indicar que aos poucos, os imóveis enormes que são frequentados hoje poderiam deixar de ter propósito, já que as compras passarão 
a ser feitas de forma online. Devido a este argumento é necessário mais uma vez voltar ao ponto de que os shopping centers no Brasil não são apenas lugares para se fazer compras. Eles são "complexos multiuso" que são utilizados para lazer, por conta de suas condições confortáveis (ar-condicionado, etc.) e por conta da segurança proporcionada, quando comparados aos passeios pelas ruas de cidades brasileiras. Entende-se que por mais que o setor possa ser digitalizado, os serviços que predominam atualmente continuarão sendo necessitados.

As dark-stores também passaram a ter maior importância durante a pandemia, substituindo os longos prazos de entrega de mercadoria resultantes de centros de distribuição longe dos centros urbanos. Essas lojas são utilizadas como centros de distribuição mais bem localizados e muitas surgiram durante a pandemia, devido à não utilização das lojas pelas regras impostas aos shopping centers (MISSIAGGIA, 2020). Assim, vemos também as novas necessidades dos consumidores, que exigem prazos cada vez menores aos lojistas, e todos os esforços sendo feitos pelos comerciantes para atenderem a essas necessidades.

As dark-stores podem impulsionar mais ainda esta tendência de marketplace das lojas e shopping centers, reduzindo a necessidade e circulação do comércio "tradicional", tornando os shopping centers em locais mais ainda focados em lazer. Assim, cresce a cada ano a necessidade do foco em lazer e em shopping centers mais voltados para o bem-estar e com mais atrações, em detrimento ao foco antigo em mais e mais lojas e marcas.

Por mais que a pandemia ainda não seja um assunto do passado, afinal continuamos tendo restrições de comércio até abril de 2021, o setor de shopping centers já avalia uma possível melhor até o final de 2021, retomando o crescimento pré-2020. A expectativa é de que o setor de shopping centers cresça por volta de $9,5 \%$ no ano de 2021 , comparado com a queda de $33 \%$ de 2020. Todavia, a ABRASCE deixa claro que devido às restrições ainda impostas e à indefinição e imprevisibilidade da Covid-19 ainda no país, nenhum crescimento é certo, apenas uma expectativa dadas as previsões atuais em relação à economia e saúde (G1, 2021).

A expectativa da associação é de que, com crescimentos importantes nos próximos anos, as perdas de 2020 devem ser recuperadas em até 3 anos. É necessário entender as indefinições do setor, principalmente as 7 listadas abaixo, de acordo com a Associação e expostas pelo G1:

1. Novas restrições de funcionamento dos shoppings;

2. Escalada da inflação nos próximos meses; 
3. Níveis de desemprego, que impacta o consumo;

4. Retomada do mercado de crédito;

5. Um possível retorno do Auxílio Emergencial;

6. Evolução das crises sanitária e fiscal;

7. Expectativa de aprovação das reformas econômicas no Congresso $(G 1,2021)$.

Por mais que não tenhamos uma situação certa e pouco volátil no ano de 2021, podemos considerar que as medidas sendo tomadas pelos shopping centers para ajustar os prejuízos de 2020 e diminuir os impactos negativos da pandemia irão resultar em números mais favoráveis para o setor.

A utilização da tecnologia será chave para entender e melhorar a experiência de um consumidor cada vez mais exigente, à procura de soluções mais rápidas e personalizadas. Os shopping centers que, durante muito tempo foram apenas "receptores" das inovações propostas pelos lojistas, terão a obrigação de inovarem cada vez mais. Assim, será possível criar uma forma de lealdade com os seus consumidores, que no passado era apenas entre consumidor e lojista (LIMA, 2021). 


\section{Análise da Iguatemi}

Neste capítulo exploraremos a história da empresa cujo valor intrínseco descobriremos através do Valuation. Entenderemos por onde a empresa começou, quais são os planos presentes e aonde ela se encontrará no seu futuro.

\subsection{História}

A Iguatemi Empresa de Shopping Centers S.A., administradora de shopping centers listada na B3, foi constituída em 1979 e é uma empresa do Grupo Jereissati. O Grupo Jereissati é uma holding que detém participação em empresas de diversos setores. A Iguatemi é a empresa do grupo que atua no ramo de shopping centers (RI IGUATEMI, 2021).

Ao longo dos muitos anos de sua história, a Iguatemi Empresa de Shopping Centers S.A. adquiriu participação em diversos shopping centers espalhados pelo Brasil. Sua primeira aquisição foi em 1979, quando comprou todos os ativos da Construtora Alfredo Matias S.A., que incluíam o shopping center Iguatemi São Paulo. Depois desta aquisição direta de shoppings já construídos, passou a montar seus próprios shoppings do zero, como o Iguatemi Campinas, Iguatemi Porto Alegre, entre outros (RI IGUATEMI, 2021).

Em 2007 a Iguatemi abriu seu capital na Bolsa de Valores de São Paulo, sendo a primeira empresa ligada a shopping centers a abrir seu capital em bolsa de valores nacional. Em um primeiro momento a empresa captou $R \$ 550$ milhões que foram direcionados para novos projetos, e, desde então, ela realizou emissões de debêntures e follow-on também na bolsa, adquirindo mais capital através do mercado e direcionando para seus projetos (RI IGUATEMI, 2021).

Os shoppings da marca lguatemi são voltados para o público $A$ e $B$, então pode-se considerar que a marca possuí um ticket médio mais elevado em relação a seus competidores, que tendem a possuir participações em shopping centers para todos os públicos. Isso também significa que os aluguéis dos shoppings estão entre os mais caros da América Latina por metro quadrado, e a 
empresa esteve em 2019, pelo $11^{\circ}$ ano consecutivo, entre as 60 marcas mais valiosas do Brasil (RI IGUATEMI, 2021).

\subsection{Operações}

A empresa Iguatemi possui participação em 14 shoppings, 2 outlets e 3 torres comerciais. Dentre estes estão os mais conhecidos Iguatemi São Paulo, JK Iguatemi, Iguatemi Porto Alegre e Fashion Outlet Santa Catarina.

A ABL Total das participações da lguatemi em shopping centers e outlets é de 437.694 metros quadrados, enquanto a $A B L$ total das participações da Iguatemi em torres comerciais é de 32.969 metros quadrados. Desta forma, a empresa tem uma $A B L$ total de 470.663 metros quadrados, através dos seus diversos estabelecimentos.

Como explicado acima, a marca Iguatemi é uma marca voltada para o público $A$ e $B$ com maior poder aquisitivo. Por isso, as marcas localizadas nos shoppings tendem a ser as de maior luxo possível como Gucci, Chanel, Burberry, entre outras.

A ideia da marca Iguatemi é pecar pelo excesso e "mimar" o consumidor o quanto for necessário para buscar a fidelidade normalmente associada apenas ao lojista final. Por esta razão, a Iguatemi vem expandido os seus serviços online e contribuindo para a melhor experiência do consumidor através de melhorias propostas e incorporadas de serviços de delivery de comida e de compras online por meio de um aplicativo próprio e curado.

As estratégias de expansão atuais estão voltadas tanto para aquisições de participações em novos shopping centers pelo Brasil, como também para aquisição de maior participação nos shopping centers que já fazem parte do portfólio da Iguatemi. A empresa busca sempre atualizar seus shopping centers com as novas tecnologias e novas tendências que aparecem no mercado no intuito de satisfazer seu público-alvo que tende a ser mais exigente devido ao ticket superior de gastos.

A empresa Iguatemi conta com diversas vantagens competitivas frente a seus concorrentes, algumas delas sendo: portfólio de shopping centers "referência" para o público-alvo de classes $A$ e $B$, um histórico favorável de crescimento sustentável e rentável, uma marca muito forte que auxilia nas parcerias com marcas de luxo fortes e reconhecidas internacionalmente, uma cultura considerada inovadora como pode-se ver pelos projetos de integração 
online recentes, e a operação de outlets premium no país, que atendem mais ainda ao seu público-alvo por ser uma alusão aos outlets frequentados no exterior.

Podemos concluir que essas estratégias e vantagens são voltadas quase que inteiramente para o seu público-alvo, e isso diferencia cada vez mais a Iguatemi das demais administradoras de shopping centers que fazem um esforço maior para atender a todas as classes, com um portfólio mais diversificado e menos concentrado. Assim, a Iguatemi garante que consegue atender a seu público-alvo com uma atenção mais dedicada e realiza os seus projetos com maior eficiência. O maior exemplo disso é a cultura inovadora da empresa com os projetos tecnológicos explicados em detalhe abaixo. Assim, a Iguatemi fortalece cada vez mais sua afinidade com seus consumidores, aumentando suas barreiras frente aos seus competidores para o mercado de maior luxo no país (RI IGUATEMI, 2021).

\subsection{Governança Corporativa}

Já em seu início na bolsa de valores, a Iguatemi, ticker IGTA3, aderiu ao maior nível de governança que podia, ingressando no segmento de listagem "Novo Mercado". Este segmento tem como alvo a maior transparência das companhias frente a seus acionistas, disponibilizando informações adicionais em comparação com o que é requisitado pela CVM. Alguns dos requisitos para que a empresa pudesse ser listada no segmento do Novo Mercado são: Capital Social composto apenas por ações ordinárias (sem ações preferenciais e units), tag-along de $100 \%$ (os acionistas podem vender suas ações pelo mesmo preço de venda dos controladores em caso de venda da companhia), um free float de, no mínimo, 25\% (ações que estão disponíveis para negociação no mercado secundário), criação de um Conselho Administrativo para decisões menos centralizadas nos diretores da empresa, entre outras exigências.

A estrutura de acionistas atual segue abaixo, retirada do site de Relações com Investidores da companhia (RI IGUATEMI, 2021):

Figura 9 - Estrutura de Acionistas da Iguatemi

\begin{tabular}{llc|}
\hline Stockholders * & No of shares (thousand) & \% of total \\
\hline Jereissati Participações & $89,345,270$ & $50.59 \%$ \\
\hline In Treasury & 477,801 & $0.27 \%$ \\
\hline Other & $86,788,507$ & $49.14 \%$ \\
\hline Total & $176,611,578$ & $100.00 \%$ \\
\hline
\end{tabular}


Fonte: RI Iguatemi, 2021

Como pode-se notar, pouco mais de $50 \%$ das ações da empresa são detidas pela sua controladora, a Jereissati Participações, holding da Iguatemi. Todavia, a empresa tem pouco menos de $50 \%$ de sua ações negociadas na B3, na categoria Other, excedendo o mínimo exigido pela CVM para empresas listadas no Novo Mercado, um sinal de que a empresa leva seu comprometimento com sua governança a sério e opta por maior liquidez de seus papéis.

Os conselhos da empresa estão divididos entre o Conselho de Diretores que é composto por seis membros, o Conselho de Administração que é composto por sete membros e o Conselho Fiscal, composto por três membros. Desta forma, a empresa assegura que seus projetos e inovações são monitorados em três níveis, garantindo maior due dilligence para seus acionistas e um filtro mais adequado para uma empresa que está em constante crescimento com novos projetos.

Quanto à distribuição de lucros da Iguatemi, a empresa paga dividendos e juros sobre capital próprio aos seus acionistas desde 2004, tendo interrompido esse histórico no ano de 2020 devido às condições desfavoráveis impostas pelo novo Coronavírus. Desta forma, podemos assumir que, caso 2020 fosse um ano comum, a empresa teria distribuído lucros normalmente, prolongando seu histórico favorável de distribuição para 16 anos. Caso o setor retome seu crescimento, como é esperado pela ABRASCE, pode-se assumir que a lguatemi distribuirá parte de seus lucros novamente em 2021.

Além da preocupação com seus acionistas, a Iguatemi visa melhorar sua Governança Corporativa através de diversas iniciativas em benefício do Meio Ambiente e relacionadas à Sustentabilidade Corporativa.

Em relação ao meio ambiente, a empresa está sempre à frente de iniciativas de economia de energia e água, constantemente substituindo suas lâmpadas por produtos mais eficientes, automatizando ar-condicionados e outros aparelhos eletrônicos menos poluentes e com menores gastos de energia, utilizando poços artesianos para menos consumo de água, instalando arejadores, vasos sanitários e outros equipamentos que economizam água e energia, entre outras iniciativas visando o bem-estar do meio ambiente.

Outras iniciativas são relacionadas aos processos logísticos utilizados pelos shopping centers, compostagem presente em alguns dos shoppings, e aderência da companhia a programas da ONU como o Woman's Empowerment 
Principle's (WEP's), parte também do Pacto Global. O objetivo da companhia é estar cada vez mais presente nas iniciativas que prezam pelo meio ambiente e que defendem a equidade de gênero, assegurando a igualdade de oportunidades para mulheres e homens no ambiente de trabalho não só dentro dos shopping centers, mas também na administração da Iguatemi. Esse movimento é evidenciado internamente pela maior participação de mulheres nas áreas de diretoria devido ao fato de que três dos seis Diretores Estatutários são, em 2021, mulheres (RI IGUATEMI, 2021). Assim, pode-se perceber que a empresa adere aos mesmos movimentos que apoiou nos últimos anos, dando mais credibilidade aos seus projetos internos de equidade de gênero.

\subsection{Novos Projetos}

Em 2019 a Iguatemi assinou uma parceria com o iFood para uma solução de organização de food delivery em seus shopping centers. Essa solução visa melhorar a experiência de todas as etapas da cadeia de suprimento, aumentando o faturamento das operações de entrega de comida dos estabelecimentos localizados nos shopping centers, implementação de uma solução eficiente de delivery tanto para restaurantes quanto para supermercados através da criação de uma área designada para entregadores, uma melhoria dos níveis de serviço das operações de delivery dos estabelecimentos, e um ganho de tempo para os entregadores que não precisarão se deslocar por dentro dos shoppings para chegar aos restaurantes (RI IGUATEMI, 2021).

Já em agosto de 2019 a companhia lançou um novo programa de integração com seu consumidor final, o Iguatemi ONE, que busca deixar mais eficiente o seu contato com os consumidores, através da jornada que a companhia apelida de "phygital" (físico + digital). Esta é uma forma também que encontraram para fidelizar os consumidores finais, os mesmos que antes eram fidelizados apenas pelas lojas que alugam espaços no shopping, não pela administradora dos imóveis em si (RI IGUATEMI, 2021).

A empresa criou ainda mais pensando no bem-estar do consumidor, praticidade e inovação, lançando o Iguatemi 365, um e-commerce próprio que reúne mais de 90 marcas curadas pela Iguatemi, com o objetivo de oferecer a experiência Iguatemi para os consumidores também fora dos shopping centers. Assim, a empresa não só garante a fidelização por meio de seu aplicativo, mas facilita a experiência do consumidor que não precisará mais entrar em 90 sites diferentes para adquirir produtos das lojas presentes nos shopping centers. Um 
aplicativo será o suficiente para facilitar a vida de todos e deixar a marca Iguatemi presente em todos os momentos da jornada de consumo do cliente, seja online ou presencialmente em um dos shopping centers (RI IGUATEMI, 2021). 


\section{Valuation Iguatemi}

Neste capítulo todas as premissas utilizadas no desenvolvimento do valuation serão explicada, embasando as razões por trás dos números e projeções.

\subsection{Premissas}

Por trás do valuation de uma empresa existem diversas premissas que 0 desenvolvedor do modelo precisa alinhar, afim de concluir o preço mais objetivo possível e que faça sentido dentro do momento econômico. É necessário pesquisar não apenas sobre a empresa e o que esta faz para crescer sua receita, mas também sobre o país em que ela está situada, números do setor, momento econômico pelo qual ela e o país estão passando, entre outras.

Essas premissas podem ser mais arrojadas, como prever um crescimento astronômico para um setor, ou elas podem ser mais conservadora, visando pensar no que pode ainda vir a acontecer, principalmente em momentos de crise como o de agora. No caso da Iguatemi, premissas bastante conservadoras foram utilizadas, pelo fato de que ainda não se sabe quando o país estará $100 \%$ novamente, o que impacta diretamente o setor de shoppings.

Outro ponto importante é que um modelo de valuation nem sempre é aquele que tem mais premissas, pelo fato de que premissas acabam sendo estimativas. Se um modelo é criado através de 10 premissas boas ele é um ótimo modelo, porém, se diversas premissas são criadas e nem todas são pertinentes, pode-se calcular diversos fatores de forma incorreta. $O$ ideal é criar premissas para aquilo que se entende e projetar de forma menos padronizada apenas aquilo que de fato terá impactos significantes no modelo.

Portanto, as premissas mais importantes e de maior impacto utilizadas foram a respeito do crescimento da empresa, CAPEX, Custo de Dívida, e Capital de Giro da Iguatemi. 


\subsubsection{Crescimento}

Nesta seção serão explicadas as premissas por trás do crescimento utilizado para a Iguatemi separado em duas partes: Crescimento em 2021 e Crescimento após 2021.

\subsubsection{Crescimento em 2021}

A divisão foi realizada desta forma por conta do ano extremamente atípico de 2020, que gerou um prejuízo muito grande para o setor de Shopping Center e, consequentemente, afetou imensamente o crescimento da Iguatemi. Por conta disso, o crescimento de 2021 foi projetado de forma mais frente ao crescimento de anos subsequentes, se esperando que o ano após o desastre seja um grande alívio para a empresa e o setor.

Desta forma, o crescimento para 2021 foi estimado utilizando uma média entre o PIB previsto para 2021 disponibilizado pelo Banco Central no Relatório FOCUS (BANCO CENTRAL, 2021), de 3,96\%, e a projeção de crescimento para o setor de Shopping Centers em 2021 disponibilizada pela ABRASCE, e referenciada no estudo do setor do capítulo 4, de 9,5\%. A projeção de crescimento para 2021 então foi de $6,73 \%$.

O crescimento de $9,5 \%$ poderia ter sido utilizado por si só, porém o racional por trás do modelo foi de tratar qualquer número com extrema cautela, visando a possibilidade ainda de mais complicações resultantes da Covid-19. Caso o momento econômico fosse mais estável, poderia ter sido estimado um crescimento mais arrojado e confiante.

\subsubsection{Crescimento após 2021}

Após este ano de recuperação maior, estimou-se que o crescimento não seria sustentável em $6,73 \%$, e, por isso, parâmetros mais baixos foram utilizados. O PIB a partir de 2023 está projetado para 2,50\% (BANCO CENTRAL, 2021) e a média histórica de crescimento dos últimos 5 anos, excluindo 2020, foi de $6,28 \%$. Com isso, a projeção de crescimento para a Receita da empresa após 2021 foi a média de 4,39\% a.a.

Mais uma vez, a premissa utilizada foi calculada de forma conservadora, muito por conta do momento ainda incerto que o país e o setor estão passando. Desta forma, pode-se entender o movimento da economia através do PIB e contar com uma média de crescimento do setor, embasando a taxa de 
crescimento da Iguatemi de uma forma neutra. Caso se acreditasse muito no setor poderiam ser utilizados números mais impactantes, e caso o pensamento fosse de que os shoppings acabariam no médio/longo prazo, números mais negativos ainda.

\subsubsection{CAPEX}

Outro ponto muito importante que auxilia no entendimento do crescimento da empresa futuro e das projeções da mesma é o CAPEX futuro estimado. O CAPEX, ou Capital Expenditures, evidencia quanto a empresa investe em si mesma, seja por aquisições ou manutenções de equipamentos, complexos, etc.

No caso da Iguatemi, existe um portfólio muito grande de shoppings que precisam de manutenções constantes, fora possíveis aquisições que podem ser feitas ao longo dos anos, utilizando CAPEX e, depois, entrando para a conta dos shoppings que precisam de manutenção. Desta forma, a projeção de CAPEX utilizada foi de $25 \%$ do Lucro Líquido da empresa em cada ano futuro.

Investimentos de capital de $25 \%$ do Lucro Líquido podem parecer muito altos, porém, como se trata de uma empresa com um Imobilizado considerável e futuras aquisições no radar, $25 \%$ pode ser estimado de forma conservadora para garantir que os movimentos futuros serão viáveis.

Outro ponto a favor do CAPEX elevado é o fato de que a Iguatemi está investindo em diversos projetos de integração física e digital, ou phygital, como evidenciado no capítulo 5 . Com isso, se torna ainda mais essencial estimar um CAPEX elevado, permitindo que a empresa cresça digitalmente de forma segura e orgânica, sem a necessidade de empréstimos para avançar com seus projetos extremamente importantes.

\subsubsection{Custo de Dívida}

O custo de dívida da empresa é essencial no cálculo do WACC, ou weighted average cost of capital, e, portanto, ímpar no valuation da empresa. Para a Iguatemi, o custo de dívida foi encontrado através da alíquota de Imposto de $22,60 \%$ e a taxa ponderada de empréstimo. A taxa de empréstimo foi calculada como $174 \%$ do CDI (RI IGUATEMI, 2021), considerando uma taxa SELIC de 6,50\%, taxa projetada pelo Relatório FOCUS para 2022 em diante. Portanto, a taxa considerada para a Iguatemi, ou Kt, foi de $11,31 \%$. Com isso, 
chega-se ao custo de capital de terceiros de $8,75 \%$, ao multiplicar o Kt por (1 alíquota de imposto)

A taxa de $174 \%$ do $\mathrm{CDI}$ foi informada pela própria empresa em seu Release trimestral de resultados (RI IGUATEMI, 2021), portanto entende-se que é a melhor taxa para se calcular a variável. O CDI é também o melhor benchmark para a mesma por conta de $84 \%$ da dívida da empresa estar atualmente atrelada ao indicados, conforme tabela abaixo:

Figura 10 - Estrutura de Dívida da Iguatemi

\begin{tabular}{|lcccc|}
\hline Dívida Total por Indexador e Prazo (RS mil) & $31 / 12 / 2020$ & $\%$ & $31 / 12 / 2019$ & $\%$ \\
\hline TR & 460.815 & $13,6 \%$ & 224.710 & $9,7 \%$ \\
CDI & 2.840 .090 & $84,0 \%$ & 2.015 .436 & $87,0 \%$ \\
Outros & 78.598 & $2,3 \%$ & 75.519 & $3,3 \%$ \\
\hline Curto Prazo & 661.969 & $19,6 \%$ & 114.904 & $5,0 \%$ \\
Longo Prazo & 2.717 .535 & $80,4 \%$ & 2.200 .760 & $95,0 \%$ \\
\hline
\end{tabular}

Fonte: RI Iguatemi, 2021

Este custo de dívida é essencial pelo fato de que é utilizado para encontrar o custo total que o Capital de Terceiros representa para a empresa. Com o custo do capital de terceiros, o custo de capital próprio é calculado e então pode-se estimar a WACC, que é a taxa de desconto utilizada para o modelo inteiro de Fluxo de Caixa Descontado.

Caso a empresa estudada tenha um poder de barganha maior ou menor, este custo de dívida oscilará, o que pode impactar fortemente no preço encontrado ao final do valuation. O custo de dívida mais elevado determina uma taxa de desconto maior e, inversamente, um custo de dívida menor resulta em uma taxa de desconto menor.

\subsubsection{Capital de Giro}

O Capital de Giro da empresa é essencial no modelo de valuation FCD. Isso se dá pelo fato de que ele é diretamente subtraído do EBITDA. Por isso, quanto maior o capital de giro para um ano, menor será o EBITDA líquido após essa subtração.

No caso da Iguatemi, as projeções de capital de giro para 2021 em diante foram encontradas somando o capital de giro do ano anterior ao Lucro Líquido 
do ano vigente, menos a parcela que será distribuída como dividendos, e subtraindo o valor devido para a projeção de CAPEX (25\% do LL).

Para calcular este valor, a projeção de distribuição de dividendos futuros também foi realizada, encontrando a média histórica dos últimos 7 anos, chegando a uma média anual de dividendos de $11,68 \%$ do Lucro líquido. A projeção de Capital de Giro se dá pela seguinte fórmula:

Capital de Giro N-1 + LL x (1-11,68\%) - CAPEX provisionado (25\% do LL)

\subsubsection{Outras Premissas}

Por mais que as premissas acima tenham sido as mais impactantes para o valuation da lguatemi, outras premissas também foram utilizadas para montar o modelo de FCD.

Os resultados financeiros e Imposto projetados para 2021 em diante foram calculados com base em uma média histórica dos 3 anos anteriores, quando comparados à Receita Líquida destes anos.

A depreciação cresceu também de acordo com a variação da Receita Líquida, baseando-se em uma alíquota de média histórica dos 7 anos anteriores a 2021.

Por fim, as deduções da Receita Bruta também foram calculadas com base na média histórica de relação com a Receita, afim de não poluir o modelo com diversas premissas que não acrescentariam ao objetivo final.

\subsection{DRE}

O elemento mais básico do modelo de valuation é a DRE projetada para anos futuros com base nas premissas utilizadas pelo investidor. No caso deste estudo, a DRE foi projetada com base nas premissas listadas acima e é evidenciada abaixo: 
Figura 11 - DRE Projetada da Iguatemi

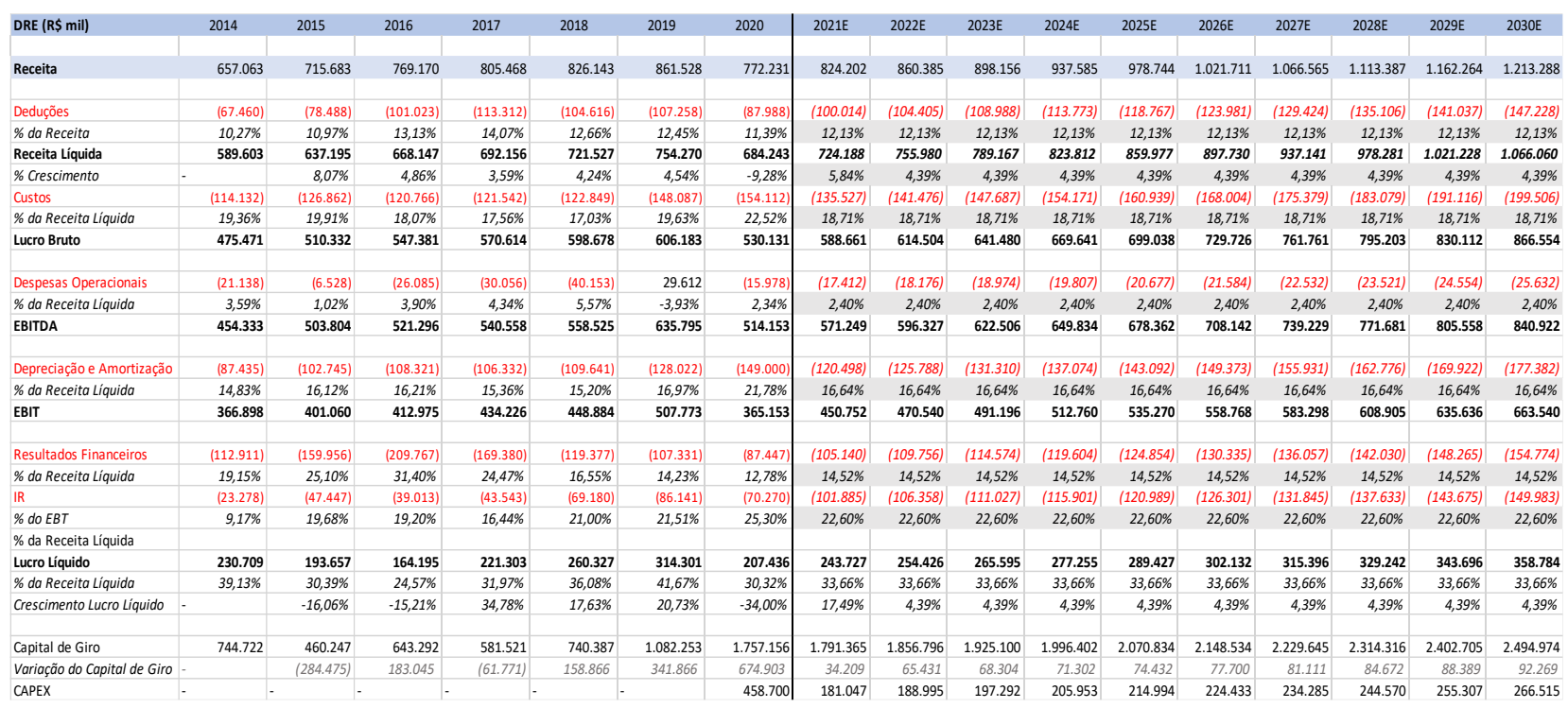

Fonte: Autor, 2021

Com base nesta DRE projetada, foi possível coletar as informações necessárias para o modelo de FCD e entender de forma mais embasada 0 momento e a trajetória da Iguatemi para a frente.

\subsection{WACC}

Após os resultados da DRE projetada até 2030, o WACC precisa ser calculado para se ter a taxa de desconto à qual os fluxos futuros serão carregados para Valor Presente. Para isso, é necessário encontrar diversos indicadores, seja através de fórmulas, Balanço Patrimonial ou pesquisas de mercado.

O primeiro indicador necessário é o Capital de Terceiros, que pode ser encontrado ao Dividir a Dívida da empresa pela soma da Dívida com o Patrimônio Líquido da Mesma. No caso da Iguatemi, em 2020 este percentual é de 52,31\%. Com este percentual, pode-se também encontrar o Capital Próprio, subtraindo $52,31 \%$ de $100 \%$ e encontrando $47,69 \%$.

O próximo indicador é o custo de capital de terceiros, indicado na seção acima como 8,75\%. Este percentual foi encontrado com base em informações divulgadas pela própria empresa (174\% do CDI de custo médio de dívida) e pela SELIC projetada para os anos futuros de $6,50 \%$, além da alíquota de $22,60 \%$ encontrada na DRE.

Por fim, o custo de capital próprio foi encontrado através da taxa de Retorno Fixo projetada (SELIC projetada a 6,50\%), taxa de retorno do mercado 
(média de retorno do lbovespa nos últimos 10 anos, de 7,86\%, calculada através do Yahoo Finance) e Beta da Iguatemi frente ao mercado brasileiro, de 0,93 (YAHOO FINANCE, 2021). Com isso, chega-se a um custo de capital próprio de $7,76 \%$.

Ao juntar o CT de $52,31 \%$, Kd de $8,75 \%$, CP de $47,69 \%$ e Ke de $7,76 \%$, chega-se a um WACC de $8,28 \%$. Portanto, o fluxo de caixa de cada ano futuro projetado será carregado para o Ano 0 com base na taxa de desconto de 8,28\%.

\subsection{Fluxo de Caixa Descontado}

Após o cálculo do WACC, é necessário calcular os fluxos de caixa futuros para se compilar o valor que a empresa adicionará com cada exercício. Para isso, o EBITDA de cada ano projetado (2021 - 2030) da DRE evidenciada acima teve a variação de capital de giro daquele ano subtraída, afim de retirar o efeito caixa do cálculo de resultado. Após essa subtração, o CAPEX e Imposto de cada ano, também evidenciados na DRE, foram subtraídos deste EBITDA líquido do Capital de Giro. Com isso, chega-se ao Fluxo de Caixa livre de cada exercício.

Através do FCL de cada exercício, é possível utilizar o WACC para carregar todos os fluxos futuros para o Ano 0 . Os fluxos são divididos por $1+$ WACC elevado ao ano do fluxo em relação à projeção (exemplo: 2023 é o Ano 3 na projeção, então a taxa é elevada a 3) e então chega-se ao Fluxo de Caixa Descontado buscado.

A Tabela abaixo evidencia estes fluxos e números utilizados:

Figura 12 - Fluxo de Caixa Descontado da Iguatemi

\begin{tabular}{|c|c|c|c|c|c|c|c|c|c|c|c|}
\hline FCLD (R\$ mil) & 2020 & $2021 \mathrm{E}$ & $2022 \mathrm{E}$ & $2023 E$ & $2024 E$ & $2025 E$ & $2026 \mathrm{E}$ & $2027 \mathrm{E}$ & $2028 \mathrm{E}$ & $2029 E$ & $2030 \mathrm{E}$ \\
\hline Ano & 0 & 1 & 2 & 3 & 4 & 5 & 6 & 7 & 8 & 9 & 10 \\
\hline EBITDA & 514.153 & 571.249 & 596.327 & 622.506 & 649.834 & 678.362 & 708.142 & 739.229 & 771.681 & 805.558 & 840.922 \\
\hline Variação Capital de Giro & (674.903) & (34.209) & (65.431) & (68.304) & (71.302) & (74.432) & (77.700) & (81.111) & (84.672) & (88.389) & (92.269) \\
\hline EBITDA líquido do CG & $(160.750)$ & 537.040 & 530.896 & 554.202 & 578.532 & 603.930 & 630.442 & 658.118 & 687.010 & 717.170 & 748.653 \\
\hline (CAPEX) & $(458.700)$ & (181.047) & (188.995) & (197.292) & (205.953) & (214.994) & (224.433) & (234.285) & (244.570) & (255.307) & (266.515) \\
\hline$(\mathrm{IR})$ & $(70.270)$ & (101.885) & (106.358) & (111.027) & (115.901) & (120.989) & (126.301) & (131.845) & (137.633) & (143.675) & (149.983) \\
\hline $\mathrm{FCL}$ & $(689.720)$ & 254.108 & 235.543 & 245.883 & 256.678 & 267.946 & 279.709 & 291.988 & 304.806 & 318.187 & 332.156 \\
\hline WACC & $8,28 \%$ & $8,28 \%$ & $8,28 \%$ & $8,28 \%$ & $8,28 \%$ & $8,28 \%$ & $8,28 \%$ & $8,28 \%$ & $8,28 \%$ & $8,28 \%$ & $8,28 \%$ \\
\hline FCLD & $(689.720)$ & 234.672 & 200.889 & 193.668 & 186.707 & 179.995 & 173.525 & 167.288 & 161.275 & 155.478 & 149.889 \\
\hline Fluxo de Caixa Perpétuo & - & 0 & 0 & 0 & 0 & 0 & 0 & 0 & 0 & 0 & \\
\hline
\end{tabular}

Fonte: Autor, 2021

Como pode-se perceber, os FCLs dos anos finais são consideravelmente reduzidos ao serem descontados pela WACC devido ao fator do tempo, que é extremamente importante no valuation. 


\subsection{Perpetuidade}

A perpetuidade é o último passo para se calcular o valor intrínseco de uma empresa, já que não se pode calcular fluxos de caixa infinitos. Através da perpetuidade, é possível calcular quanto estes fluxos "valeriam" caso a empresa continuasse existindo para sempre, sem que seja necessária a conta ano por ano.

No caso da Iguatemi, o último Fluxo de Caixa Livre, de 2030, foi utilizado como base para a conta da perpetuidade por ser o último FCL disponível. Este FCL foi multiplicado pela taxa de crescimento perpétuo calculada, ou $g$, de $4,39 \%$ (mesma taxa utilizada para o crescimento dos anos após 2021). O número encontrado de 346.737 foi então dividido pela subtração do crescimento perpétuo de $4,39 \%$ pelo WACC de $8,28 \%$. Por fim, este número 8.908 .455 foi dividido pela WACC elevada a 10, último ano do modelo disponível, do qual utilizamos o FCL.

Com isso, o valor perpétuo da Iguatemi fica igual a 4.020.042.000 carregado ao Ano 0 . Este valor é somado aos demais fluxos de caixa descontados dos anos anteriores na projeção e encontra-se o VPL total da empresa no Ano 0, de 5.133.708.000.

\subsection{Valor por Ação}

Após todos os cálculos explicados acima, o valuation chega ao seu último passo, descobrir o valor intrínseco da Iguatemi Shopping Centers S.A. Para isso, o VPL total do Ano 0 é somado com a Dívida Líquida da empresa (Dívida subtraída das Disponibilidades) e somado ao Equity da mesma. Estes números são evidenciados em 2020 do Balanço Patrimonial abaixo: 
Figura 13 - Balanço Patrimonial da Iguatemi

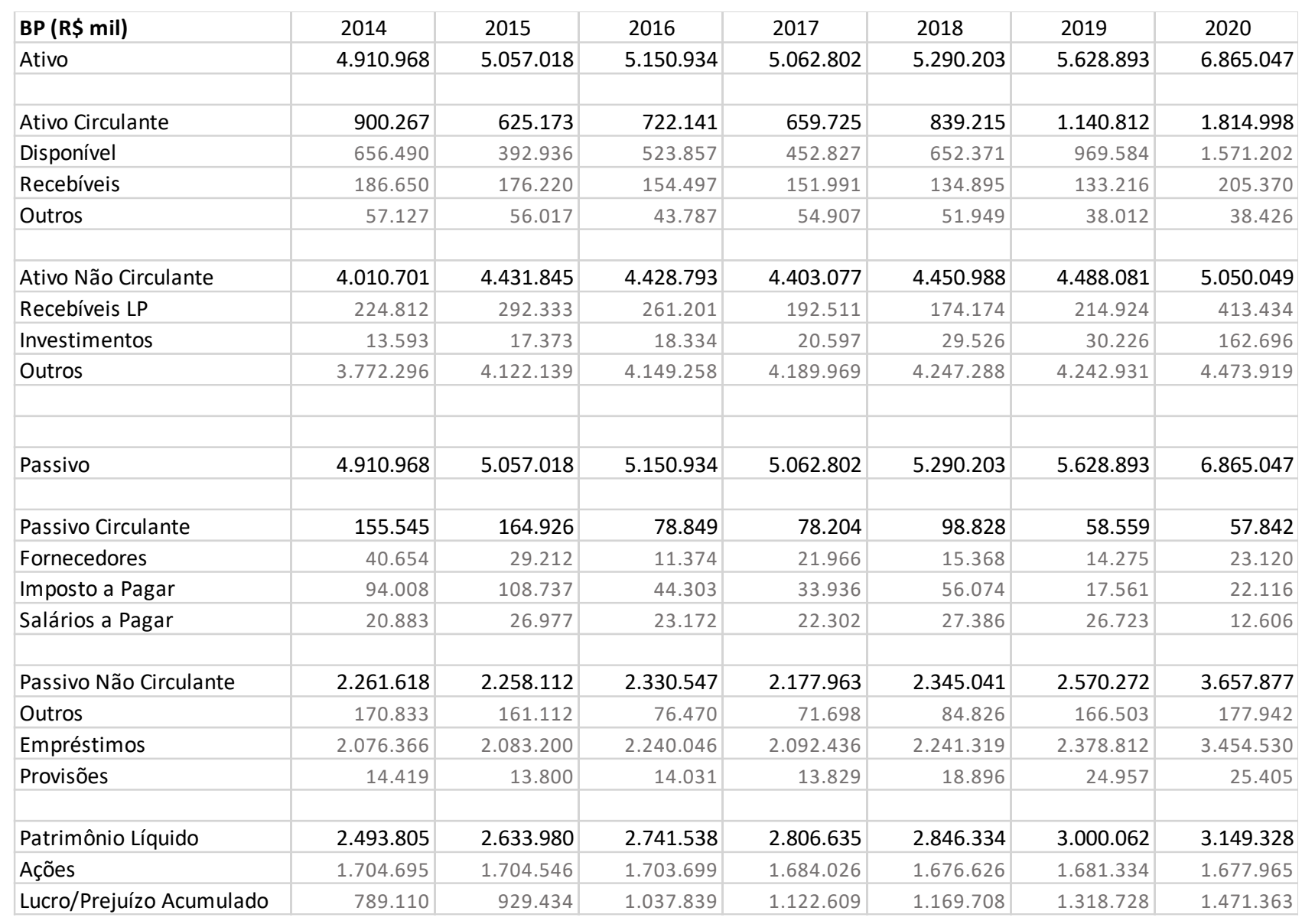

Fonte: RI Iguatemi, 2021

Ao somar estes valores, o Valor Íntrinseco da empresa chega a $\mathrm{R} \$$ 6.399.708.000 que, quando dividido pelas 176.611 .578 ações, equivale a um Valor unitário de $\mathbf{R} \mathbf{3 6 , 2 4}$ para IGTA3, conforme evidenciado abaixo:

Figura 14 - Valor Justo de IGTA3

\begin{tabular}{|l|r|}
\hline VPL (com a Perpetuidade) & 5.133 .708 \\
\hline (Dívida Líquida) & $(1.883 .328)$ \\
\hline Equity & 3.149 .328 \\
\hline Valor em R\$ mil & $\mathbf{6 . 3 9 9 . 7 0 8}$ \\
\hline Quantidade de Ações & 176.611 .578 \\
\hline Valor por Ação em R\$ & $\mathbf{3 6 , 2 4}$ \\
\hline
\end{tabular}

Fonte: Autor, 2021

Com isso, conclui-se o processo de valuation da Iguatemi Shopping Centers S.A. No dia 31 de março de 2021, a ação estava cotada a $R \$ 37,40$, indicando uma precificação $3,20 \%$ maior do que o valor intrínseco descoberto 
através do valuation. Ao comparar o preço com o valor de mercado do fechamento do primeiro trimestre de 2021, pode-se entender que o mercado também precificava este papel de forma conservadora, devido ao momento ainda incerto. Hoje, 4 de junho de 2021, a ação já chega a $R \$ 43,40$ evidenciando o otimismo do mercado nas últimas semanas com os avanços na vacinação e nas melhorias do cenário externo. 


\section{Considerações Finais}

Este estudo teve como objetivo encontrar o valor intrínseco da Iguatemi Shopping Centers S.A., ao avaliar sua situação financeira, projetos em andamento e mercado em que a empresa atua. Os dados foram tratados da forma mais objetiva e clara possível, afim de evitar qualquer posicionamento a favor de qualquer lado, mas sim o cálculo fiel às perspectivas e crescimento viável da empresa.

As premissas utilizadas foram baseadas em fatores externos e internos à companhia, além de dados projetados para o país como um todo. Estas também foram embasadas da forma mais conservadora possível, afim de evitar que fossem projetadas fora da realidade em que a empresa de fato vive. Caso estivéssemos passando por um momento menos incerto no setor de shopping centers, as projeções de Receita certamente poderiam ser maiores e então resultar em um valor unitário mais relevante, como se vê o negociado nas últimas semanas na B3.

A decisão de comparar o preço unitário encontrado com o fechamento do $1^{\circ}$ Trimestre de 2021 foi justamente por este fato, ne época em que o estudo foi iniciado as perspectivas eram outras. Hoje, já se pode perceber uma melhora não só no cenário local, mas diversas melhorias no cenário externo, o que indica que a vacinação levará a uma retomada e os shoppings serão extremamente beneficiados. Em março ainda não se sabia ao certo quando esta retomada viria, muito pelo fato de que a previsão para vacinação era ainda muito incerta, comparada a hoje quando já temos calendários de vacinação até novembro. Esta maior previsibilidade auxiliou no aumento das ações, mas, por via das dúvidas, o estudo foi realizado ainda com as perspectivas negativas e pontos pessimistas à frente na pauta.

O valor intrínseco encontrado foi fiel ao momento mais pessimista do mercado, principalmente em relação a shopping centers, e mostrou que, ao projetar fluxos futuros de forma conservadora, chegamos à mesma conclusão que o restante do mercado. O preço encontrado de $R \$ 36,24$ é apenas 3,20\% menor do que o preço do fechamento do $1^{\circ}$ Trimestre de 2021 , de $\mathrm{R} \$ 37,40$. 
A Iguatemi se mostrou uma empresa com resultados e ambição bastante sólidos, principalmente ao olharmos para os projetos digitais que a empresa já iniciou, como o Iguatemi One. Desta forma, a empresa não precisará contar com a fidelização dos clientes com as lojas localizadas em seus shoppings, mas poderá contar com a fidelidade à qualidade da marca Iguatemi. Acredito que ao avaliar a empresa futuramente será possível perceber os avanços relacionados a estes projetos, e os números encontrados certamente serão mais imponentes do que os de 2020 para trás.

O estudo em si gerou diversos conhecimentos e aprofundou muitos dos temas estudados ao longo dos 4 anos de faculdade de Administração de Empresas na PUC-Rio. O principal aprendizado foi montar um modelo de valuation na prática, uma vez que havia tratado apenas em partes nas aulas de Finanças. A pesquisa de mercado também foi extremamente importante para entender como se deve olhar para uma empresa e como quantos mais ângulos temos, melhor é o resultado por se entender a situação por inteiro. 


\title{
8 Referências Bibliográficas
}

ABRASCE. Números do Setor. São Paulo, 2021 Disponível em: $<$ https://abrasce.com.br/numeros/setor/>. Acesso em: 19 de março. 2021.

\begin{abstract}
ARRUDA, E. Pandemia desacelerou setor de shoppings centers em 2020 no Brasil. CACB, Brasília, 29 jan. 2021. Disponível em: $<$ https://cacb.org.br/pandemia-desacelerou-setor-de-shoppings-centers-em2020-no-brasil/>. Acesso em: 12 de março de 2021.
\end{abstract}

B3. Índice Small Caps (SMLL B3). São Paulo, 2021 Disponível em: <http://www.b3.com.br/pt_br/market-data-e-indices/indices/indices-desegmentos-e-setoriais/indice-small-cap-smll.htm>. Acesso em: 2 de junho. 2021.

BANCO CENTRAL. Focus - Relatório de Mercado. São Paulo, 2021 Disponível em: <https://www.bcb.gov.br/publicacoes/focus>. Acesso em: 2 de junho. 2021.

BREALEY A. R., MYERS C.S., ALLEN F., Principles of Corporate Finance $-12^{a}$ Edição. Nova lorque: McGraw-Hill Education, 2017. P 34 e 85.

DAMODARAN, A. Avaliação de empresas - $2^{2}$ Edição. São Paulo: Pearson Prentice Hall, 2007.

FASHION NETWORK. Confira 5 Tendências para o setor de shoppings no Brasil. São Paulo, 2017 Disponível em: $<$ https://br.fashionnetwork.com/news/Confira-5-tendencias-para-o-setor-deshoppings-no-brasil,788139.html>. Acesso em: 28 de março. 2021.

G1. Faturamento de shoppings centers tem queda de $33 \%$ em 2020 , diz Abrasce. Rio de Janeiro, 2021 Disponível em: <https://g1.globo.com/economia/noticia/2021/01/28/faturamento-de-shoppingscenters-tem-queda-de-33percent-em-2020-diz-abrasce.ghtml>. Acesso em: 12 de março. 2021.

LIMA, B. Como o setor de shoppings está se reinventando para superar a crise? Consumidor Moderno, São Paulo, 16 fev. 2021. Disponível em: <https://www.consumidormoderno.com.br/2021/02/16/setor-de-shoppingsreinventando-superar-crise/>. Acesso em: 12 de março de 2021.

MERCADO E CONSUMO. Shoppings registram aumento de 7,9\% nas vendas em 2019. São Paulo, 2020 Disponível em: <https://mercadoeconsumo.com.br/2020/01/30/shoppings-registram-aumento-de79-nas-vendas-em-2019/>. Acesso em: 19 de março. 2021.

MISSIAGGIA, M. Dark stores, o formato que acelerou o futuro do ecommerce. Diário do Comércio, São Paulo, 19 ago. 2020. Disponível em: $<$ https://dcomercio.com.br/categoria/negocios/dark-stores-o-formato-queacelerou-o-futuro-do-e-commerce>. Acesso em: 12 de março de 2021. 
RI IGUATEMI. Iguatemi. São Paulo, 2021 Disponível em: <https://ri.iguatemi.com.br/Default.aspx>. Acesso em: 10 de abril. 2021.

SOBRAL, F. PECI, A. Administração: teoria e prática no contexto brasileiro. - $2^{\text {a }}$ Edição. São Paulo: Pearson Education do Brasil, 2013. P. 466.

STATUS INVEST. Status Invest. São Paulo, 2021 Disponível em: <https://statusinvest.com.br>. Acesso em: 28 de março. 2021.

XP MALLS. Mercado de Shopping Centers. São Paulo, 2018 Disponível em: $<$ https://xpmalls.riweb.com.br/show.aspx?idCanal=YkNR8TsTBrH+xwlvw1NINg= =>. Acesso em: 12 de março. 2021.

YAHOO FINANCE. Iguatemi Empresa de Shopping Centers S.A. (IGTA3.SA). Nova lorque, $2021 \quad$ Disponível em: <https://finance.yahoo.com/quote/IGTA3.SA?p=IGTA3.SA\&.tsrc=fin-srch>. Acesso em: 2 de junho. 2021. 